\title{
Correction to: Nanobiotechnology Approach for the Remediation of Environmental Hazards Generated from Industrial Waste
}

\author{
Mounika Gudeppu, Krishnapriya Madhu Varier, Arulvasu Chinnasamy, \\ Sumathi Thangarajan, Jesudas Balasubramanian, Yanmei Li, \\ and Babu Gajendran
}

Correction to: Chapter 13 in: R. Saravanan et al. (eds.), Emerging Nanostructured Materials for Energy and Environmental Science, Environmental Chemistry for a Sustainable World 23, https://doi.org/10.1007/978-3-030-04474-9_13

The original version of this chapter was revised; the affiliation for Arulvasu Chinnasamy and Sumathi Thangarajan had been interchanged.

The affiliations have been updated now as:
A. Chinnasamy
Department of Zoology, University of Madras, Chennai, India
S. Thangarajan
Department of Medical Biochemistry, Dr. ALM PGIBMS, University of Madras, Chennai, India

